\title{
Designação de lectótipos de algumas espécies sul-americanas de Anthidium Fabricius (Hymenoptera, Megachilidae) $^{1}$
}

\section{Danúncia Urban ${ }^{2}$}

\begin{abstract}
Designation of Lectotypes of some South American species of Anthidium Fabricius (Hymenoptera, Megachilidae). In the collection of Museu de Zoologia, Universidade de São Paulo, São Paulo, there are specimens from Schrottky's collection which constitute the sintypes of some of the species of Anthidium that he described in 1910. Studying this genus, it is pertinent to designate the Lectotypes of these species, as follows: Anthidium cuzcoense Schrottky, 1910; Anthidium garleppi Schrottky, 1910; Anthidium nigerrimum Schrottky, 1910; Anthidium patagonicum Schrottky, 1910, and Anthidium peruvianum Schrottky, 1910. The lectotype of Anthidium kuscheli Moure,1957, deposited in the collection of Departamento de Zoologia, Universidade Federal do Paraná, Curitiba, is also here designated.

KEY WORDS. Hymenoptera, Megachilidae, Lectotypes. Anthidium, taxonomy
\end{abstract}

Entre abelhas gentilmente cedidas para estudo pelo Museu de Zoologia da Universidade de São Paulo (MZSP), encontrou-se espécimens que foram trabalhados por SCHROTTKY (1910) e que constituem síntipos de algumas espécies descritas por ele dentro de Anthidium Fabricius, 1804. Para não haver problemas futuros quanto à identificação correta das espécies, achamos conveniente designar os respectivos lectótipos, da mesma forma, para uma espécie descrita por MOURE (1957), cujos síntipos se encontram depositados na Coleção de Entomologia Pe. J.S. Moure do Departamento de Zoologia da Universidade Federal do Paraná (DZUP).

\section{Anthidium cuzcoense Schrottky, 1910}

Figs 1-2

Anthidium cuzcoënse [sic] Schrottky, 1910: 268.

Lectótipo fêmea, aqui designado, com as seguintes etiquetas: "Cuzco /Peru $13500 \mathrm{~m} /$ mai [19]08" tendo uma etiqueta colada do outro lado "Type"; "Anthidium [fêmea] /cuzcoënse Schrottky /C. Schrottky det. 1910"; "102.199"; "Anthidium lcuzcoënse /Type Schr. /Det. J.S. Moure, 1957"; "LECTÓTIPO"; "Anthidium lcuzcoense /LECTÓTIPO/Urban det. 2000". Paralectótipo macho com os mesmos dados de procedência e identificação e a etiqueta: "102.200". Estão depositados na Coleção do Museu de Zoologia da Universidade de São Paulo (MZSP).

1) Contribuição número 1201 do Departamento de Zoologia, Universidade Federal do Paraná.

2) Departamento de Zoologia, Universidade Federal do Paraná. Caixa Postal 19020, 81531-990 Curitiba, Paraná, Brasil. Bolsista do CNPq. 
Lectótipo fêmea com os seguintes desenhos amarelos na cabeça: nódoas pequenas nos cantos do vértice; paroculares inferiores quase até o nível dos alvéolos; clípeo, excetuando grande nódoa preta basal de contorno discal arredondado e a margem também preta. Antenas pretas e tégulas ferrugíneas; pernas pretas com estria amarela nas tíbias; do segundo ao quinto tergo com quatro nódoas amarelas ovaladas em cada tergo; o primeiro com faixas laterais em arco voltado para a frente e separadas por área preta menor que as faixas; sexto tergo com duas grandes máculas quadrandulares. Ápice do sexto tergo sem espinhos, com angulosidades nos lados e expansão bissinuosa no meio. Pilosidade branca, com pêlos castanho-escuros no vértice e, no mesoscuto os pêlos castanhos mesclados aos brancos; basitarsos com densa pilosidade ocultando o tegumento; escopa ventral esbranquiçada.

Paralectótipo macho com amarelo no clípeo, paroculares inferiores e nódoa pequena nos cantos do vértice; mesosoma preto, pernas pretas com estria amarela nas tíbias; basitarsos amarelos e tarsômeros méleos. Tergo basal com duas nódoas amarelas bem laterais, do segundo ao quinto com quatro nódoas amarelas em cada tergo, ovaladas e com recortes posteriores levemente arredondados, as duas fileiras medianas com o recorte látero-posterior e as fileiras laterais com recorte médio-posterior, no quarto e quinto tergos as nódoas laterais com outro pequeno recorte ântero-lateral; no sexto tergo duas nódoas amarelas grandes e duas laterais muito reduzidas; tergo distal preto. Sétimo tergo com lobos laterais arredondados na ponta, quase tão largos como o recorte basal em arco que os separam do espinho mediano.

\section{Anthidium garleppi Schrottky, 1910}

Fig. 3

Anthidium garleppi Schrottky, 1910: 267.

Lectótipo fêmea, aqui designado, com as seguintes etiquetas: "18.113"; Apurimac / Peru"; "Anthidium [fêmea] / garleppi Schrottky /C. Schrottky det. 1910". "102.208”; "LECTÓTIPO”; "Anthidium/garleppi/LECTÓTIPO/Urban det. 2000". Depositado na Coleção do Museu de Zoologia da Universidade de São Paulo.

Cabeça preta com duas nódoas amarelas pequenas nos cantos do vértice; antenas, mesosoma, tégulas e pernas pretos; padrão de colorido dos tergos como em Anthidium cuzcoense. Sexto tergo armado distalmente com quatro espinhos eqüidistantes, os dois laterais dirigidos para trás e os outros arqueados para o meio; escopa preta.

\section{Anthidium nigerrimum Schrottky, 1910}

Fig. 4

Anthidium nigerrimum Schrottky, 1910: 269.

Lectótipo fềmea, aqui designado, com as seguintes etiquetas: "Type"; "Cuzco /Peru /3500m /mai [19]08"; "102.207"; "Anthidium [fềmea] / nigerrimum/Schrottky /C. Schrottky det. 1910"; "Stenanthidium /nigerrimum [fềmea] / (Schr.) / P. Moure det. 1949". "LECTÓTIPO"; "Anthidium Inigerrimum /LECTÓTIPO/Urban det. 2000". Depositado na Coleção do Museu de Zoologia da Universidade de São Paulo. 

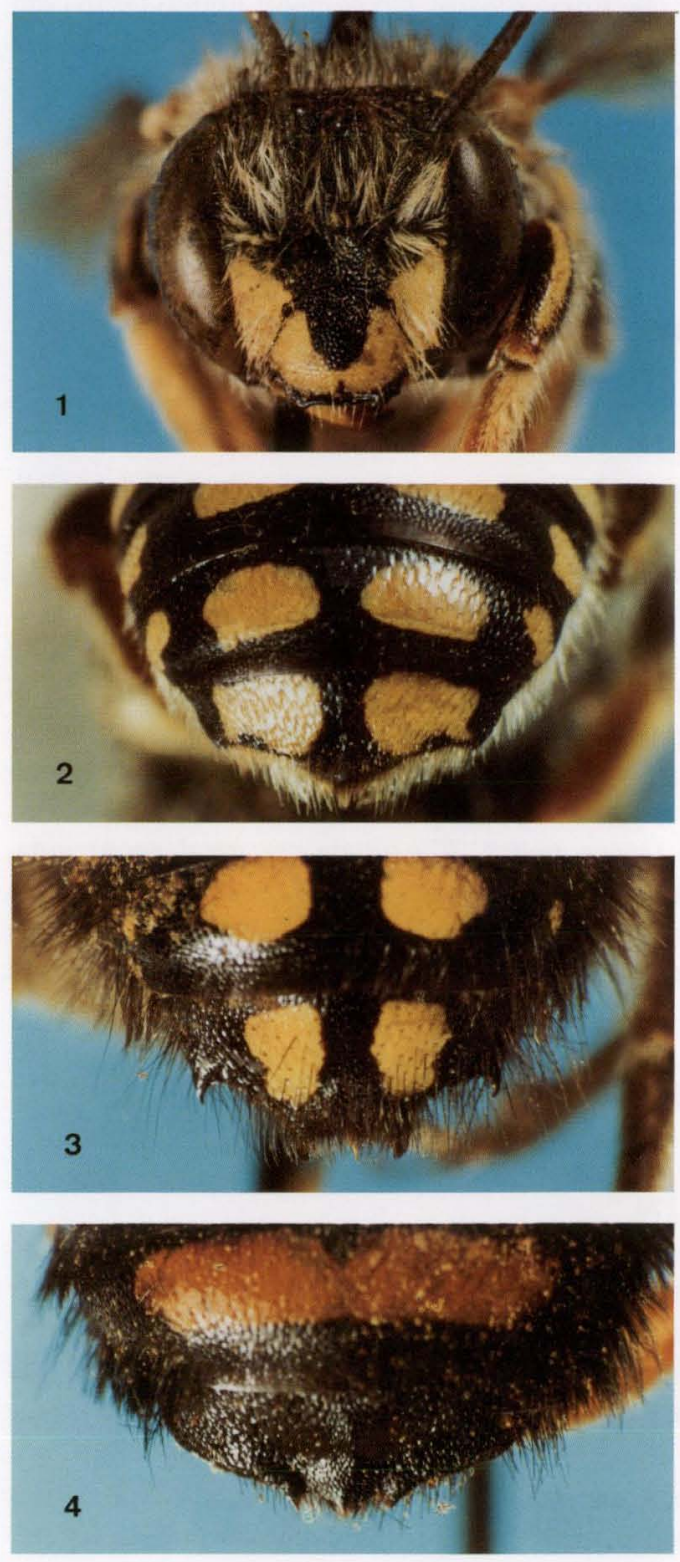
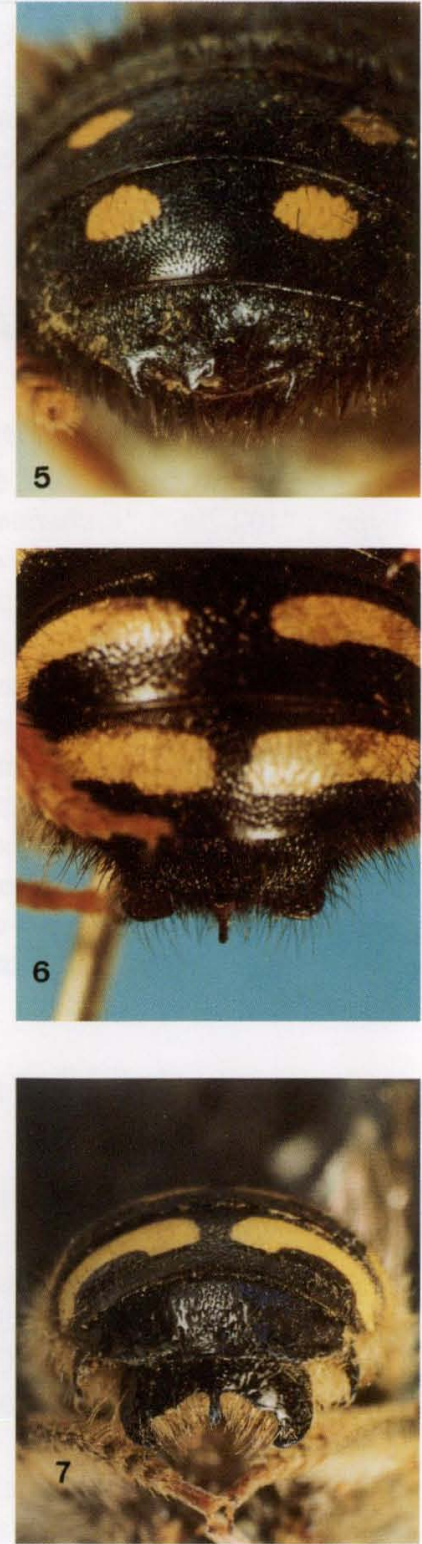

Figs 1-7. Lectótipos. (1-2) Anthidium cuzcoense; (3) Anthidium garleppi; (4) Anthidium nigerrimum; (5) Anthidium patagonicum; (6) Anthidium kuscheli; (7) Anthidium peruvianum. 
Tegumento predominante preto incluindo as antenas e tégulas, com pequena nódoa amarela nos cantos do vértice; tíbias e tarsos ferrugíneos; quinto tergo com faixa larga ferrugíneo-amarelada ocupando somente a face dorsal, o contorno anterior mais estreito no meio. Sexto tergo com pequena área mediana armada com três espinhos finos, o mediano alargando para a base em direção aos laterais. Pilosidade preta, passando a ferrugínea nas tíbias e tarsos; escopa preta.

Margem cortante das mandíbulas incompleta, alguns dos dentes muito desgastados.

\section{Anthidium patagonicum Schrottky, 1910}

Fig. 5

Anthidium patagonicum Schrottky, 1910: 269.

Lectótipo fêmea, aqui designado, com as seguintes etiquetas: "Patagonia"; "Type"; "102.206"; "Anthidium [fêmea]/patagonicum/Schrottky /C. Schrottky det. 1910" " "LECTÓTIPO”; “Anthidium /patagonicum /LECTÓTIPO/Urban det. 2000”. Depositado na Coleção do Museu de Zoologia da Universidade de São Paulo.

Tegumento preto, exceto faixa amarela estreita no vértice, não expandida acima dos olhos e fracamente interrompida no meio; antenas ferrugineas com a ponta enegrecida; tégulas ferrugíneo-claras; tíbias e tarsos ferrugíneos; primeiro tergo com nódoas amarelas bem laterais, terceiro com nódoas minúsculas um pouco mais dorsais, no quarto e quinto tergos as nódoas pouco maiores e mais próximas uma da outra; segundo e sexto tergos pretos. Pilosidade em geral enegrecida, castanho-amarelada no escapo, amarelo-palha no vértice e mesoscuto, ferrugínea nas tíbias e tarsos. Sexto tergo com dois espinhos laterais finos um pouco arqueados para o meio e dois espinhos medianos largos e angulosos separados por pequena concavidade; escopa preta.

\section{Anthidium peruvianum Schrottky, 1910}

Fig. 7

Anthidium peruvianum Schrottky, 1910: 270.

Lectótipo macho, aqui designado, com as seguintes etiquetas: "Apurimac / Peru" e colado na outra face da etiqueta "Type"; "102.198"; "Anthidium [macho] / peruvianum /Schrottky /C. Schrottky det. 1910"; "Anthidium /perivianum / Schr. /Det. J.S. Moure, 1957”. "LECTÓTIPO”; “Anthidium /peruvianum/LECTÓTIPO /Urban det. 2000”. Depositado na Coleção do Museu de Zoologia da Universidade de São Paulo.

Cabeça preta exceto clípeo, paroculares inferiores e nódoa pequena nos cantos do vértice amarelos, antenas pretas; mesosoma e pernas pretos, tégulas enegrecidas. Três tergos basais com faixa amarela completa, bastante larga nos flancos e com recortes arqueados posteriormente, no terceiro estreitada no meio; quarto e quinto com faixas laterais amarelas recortadas posteriormente; os dois últimos tergos pretos. Sétimo tergo com lobos laterais estreitos na ponta e arqueados para o meio, a seguir alargando em ângulo muito aberto até o espinho mediano. 


\section{Anthidium kuscheli Moure, 1957}

Fig. 6

Anthidium kuscheli Moure, 1957: 213.

Lectótipo macho, aqui designado, com as seguintes etiquetas: "Tipo"; "Poroma /10.3.48 /Chile"; "kuscheli"; "Anthidium /kuscheli m."; "P. Moure det. 1949". "LECTÓTIPO"; "Anthidium /kuscheli /LECTÓTIPO /Urban det. 2000". Dois paralectótipos, uma fêmea e um macho com as mesmas etiquetas de procedência e de identificação. Depositados na Coleção Pe. J.S. Moure, Departamento de Zoologia, Universidade Federal do Paraná.

Lectótipo macho, preto com amarelo-pálido no clípeo, paroculares inferiores e pequena nódoa nos cantos do vértice; antenas ferrugíneas até o terceiro flagelômero e no restante enegrecidas; tíbias e tarsos ferrugíneos; mesosoma preto; cinco tergos basais com faixas amarelas laterais estreitas, no quinto com pequeno espaço preto entre as faixas. Sétimo tergo com lobos tão largos como o recorte semicircular basal que os separam do espinho mediano.

Paralectótipo fêmea com as faixas amarelas do quinto tergo quase unidas medialmente. Sexto tergo com espinhos laterais curtos e largos, no meio com o contorno bissinuoso; escopa ventral preta.

AGRADECIMENTOS. Ao Prof. Dr. Albino Morimasa Sakakibara pelas fotos que ilustram o trabalho.

\section{REFERÊNCIAS BIBLIOGRÁFICAS}

Moure, J.S. 1957. Nuevos Anthidiinae para Chile. Rev. Chilena Ent. 5: 205-218.

Schrottky, C. 1910. Neue südamerikanische Arten der Bienen Gattung Anthidium Fabr. Wien ent. Ztg. 29 (7-8): 267-271.

Recebido em 23.III.2000; aceito em 07.IV.2001. 